\title{
The effect of hydroxyalkyls, derivatives of 2- hydroxypropane-1.2.3-tricarboxylic acid, on flammability and thermal properties of PUR-PIR foams
}

\author{
Liszkowska Joanna ${ }^{1}$ Czupryński Bogusław ${ }^{1}$ • \\ Paciorek-Sadowska Joanna ${ }^{1}$
}

Received: 27 June 2016/Revised: 3 July 2017/Accepted: 19 September 2017/

Published online: 30 October 2017

(C) The Author(s) 2017. This article is an open access publication

\begin{abstract}
This article describes the results of multidirectional research on the flammability and heat properties of rigid polyurethane-polyisocyanurate foams (PUR-PIR). They were produced, using new three polyols (citrates) obtained from 2-hydroxypropane-1.2.3-tricarboxylic acid (citric) and selected diols: propane-1.2diol (with and without a catalyst) and pentane-1.5-diol (with catalyst). The esterification products enabled the creation of PUR-PIR foams. Their oxygen index and retention were comparable to the non-modified foam. Foam flammability was measured in the new products with the compound. It has been confirmed that the foam modification does not affect its oxygen index, which was about $24 \%$. The retention (residue after burning foams) was in the range of 80-96\%. It has been estimated that the addition of citrates shortens the PUR-PIR foam burning time. The addition of 0.1 or 0.3 eq. of the new compounds caused the prolongation of the occurring time for the maximum temperature during burning, from $13 \mathrm{~s}$ (reference foam without citrate) to $14 \mathrm{~s}$ (foam obtained from citrate synthesized from citric acid and propane-1.2-diol with no catalyst). It also shortened the time to $11 \mathrm{~s}$ (foam with citrate synthesized with propane-1.2-diol, using catalyst) and to $10 \mathrm{~s}$ (foam included citrate obtained from citric acid and pentane-1.5-diol, with catalyst). The ratio of $\mathrm{HRR}_{\max }$ value to the time in which it was reached is in the range of 9.14-11.75 k W/m² $\mathrm{s}$. There was no observable correlation between the oxygen index (OI) and the amount of citrate in the foam. After the modification of PURPIR foam with citrate compounds, similar IO values can be observed in the range of $23.8-24.0 \%$ (for reference foam was $23.9 \%$ ).
\end{abstract}

Keywords Rigid PUR-PIR foams · Polyols · Flammability · Citric acid $\cdot$ Oxygen index $\cdot$ Retention $\cdot$ Cone calorimeter

Liszkowska Joanna

liszk@ukw.edu.pl

1 Kazimierz Wielki University, Bydgoszcz, Poland 


\section{Introduction}

Polyurethanes (including foams) are widely used in various fields. Most often they are used in construction (construction materials and technologies, appliances, interior decoration and equipment), in household appliances and audio/video devices, and also as packaging and in transport industries [1]. Because of their wide use in construction, it is very important that the materials match the restrictions of the building. They need to be designed to ensure limited spread of flame and smoke inside a building, as well as the neighboring buildings, in case of fire [2]. Fires can be caused not only by the type of used materials, but also by the way of their storing. Foam polymers are easily consumed by the flame due to their developed surface $[3,4]$. When porous materials burn (e.g. polyurethane foams), the fire progression is very rapid. The materials start undergoing thermal disintegration at relatively low temperatures - around $180-400{ }^{\circ} \mathrm{C}$. Heat, smoke, soot and toxic gases are generated (products of thermal oxidation decomposition, and complete and not complete burning). The flame burning process of polymers and the formation of flammable compound over its surface are the deciding factors in fire expansion in closed spaces [5-8]. Human life depends on the fire type, concentration and conditions [9].

The improvement of requirements in polyurethane properties is mostly driven by the need to decrease the flammability of the materials [9] and fire attributes [10-12]. Fire attribute is a numerical value, a function of parameters in a composition for which they are measured. The following are included: heat release rate (HRR), smoke extinction area (SEA), the toxicity of burning gas products, the degree of residue charring [Char yield (CY)], material combustibility and burning index (BI). It has to be noted that the shape of HHR curve is dependent on the sample's thickness. Thin elements burn fast and intensively, and the type of material they are made of almost does not matter [5, 11-14]. From fire perspective, a polymer is safer if it has lower HRR and SEA values and higher OI (oxygen index), CY and retention (mass remaining after burning).

One component has a high influence on the shaping of PUR properties- the polyol. The appropriate polyol results in expanded surface layer, which insulates thermally the following polyol layers and does not allow the fire to access them $[9,15,16]$. Polyols containing phosphorous, nitrogen or halogens, flame retardant compounds bonded with polymer during synthesis or cross-linking, are usually used for polyurethane production. In general, making materials flame retardant is a process of their self-extinguishing or their non-flammability, due to high thermal stability and low heat release abilities [10]. The burning of $1 \mathrm{~kg}$ of polyurethane foam in $30 \mathrm{~m}^{3}$ room can cause life threatening fume concentration to be exceeded after $90 \mathrm{~s}$. Around $0.03-0.05 \mathrm{~m}^{3}$ of hydrogen cyanide is produced [9, 17]. In addition, $\mathrm{CO}, \mathrm{CO}_{2}, \mathrm{NO}_{2}$ are created during foam burning, and diisocyanates are produced during the decomposition. Additionally, the surface active compounds (silicones) present in polyurethanes emit $\mathrm{SiO}_{2}$ and $\mathrm{HCOOH}$ [18]. The threat is dependent on their type, concentration, exposure time in the polluted atmosphere and physical health of a human being. Other factors include fire conditions, i.e. space dimensions, fire hazard, the degree of flammable material fragmentation, 
ventilation. The absorption can happen via respiratory tract, gastrointestinal tract and skin $[12,17]$.

Materials, such as rigid polyurethane foams, undergo a so-called oxidation. They do not soften and to not melt, however, create a hard porous charred structure [5]. Polymers modified to be flame retardant usually generate larger volumes of thicker smoke during fire than non-modified polymers. When synthesizing materials used in areas which are directly life threatening, there needs to be a balance between their functionality and potential fire risk. That is why researches are being conducted on new types of retardants based on tin compounds, synergic combinations of nitrogen and phosphorous [4] and manganese, molybdenum, boron or silicon [19-24]. Nowadays, the most common method of making materials flame retardant is using nanofillers and thus creating a so-called nanocomposite [25-35]. Because the amount of added nanofillers is so small, there is a chance that the strength properties will not suffer. Polymer nanocomposites have also better thermal stability in comparison to the flame retardant polymers produced with traditional methods. During their burning, less carbon monoxide and soot is being produced [36-40].

Thermal resistance and stability determine the thermal characteristics of the polymers [5]. Thermal stability is the temperature in which chemical destruction of the polymer starts. Thermal resistance is the maximum temperature in which the material retains its useful mechanical properties. When comparing the burning products of wood and polyurethane foam which have not been made flame retardant, it has been determined that there is no significant difference between the smoke toxicity from either one of the burning materials. The toxicity of volatile products of their burning is in the proximity of the toxicity of regular burning materials used for heating [41].

The article is a continuation of the publications in Polymer Bulletin [42] and in Chemical Engineering and Equipment [43] and other [44-47], which discusses preparation, construction and structure of the new compounds. The aim of the conducted research was the production of new polyols for rigid PUR-PIR foams and creating new recipe for obtaining polyol premix. These main compounds were obtained using citric acid, cheaper than the ones currently used on the market: adipic acid, phthalic anhydride, AGS (a mixture of carboxyl acids), vegetable oils, castrol oil. Rated properties of foams (flammability and thermal properties) with novel compounds. The presented article examines the effect of the new compounds on the foam flammability and the softening point. The aim of the study was to determine the new E compounds (cheaper and greener than the industrial ones) which do not impair the selected properties of the foams compared to the properties of foam blown with only the petrochemical polyol.

\section{Experimental}

\section{Materials}

Oligoesterol with trade name Rokopol RF551 poly(oxypropylene)diol with hydroxyl number $420 \mathrm{mg} \mathrm{KOH} / \mathrm{g}$, molecular weight $=660$ ) product of Chemical 
Plants PCC Rokita S.A. in Brzeg Dolny was used to prepare rigid PUR-PIR foams. Three compounds containing hydroxyl groups were also used: E14, E15, E16, produced in Department of Chemistry and Polyurethanes' Technology. Technical polymeric polyisocyanate Ongronat 30-20 was used as a cross-linking compound (BorsodChem, Hungary). Its main component is $4.4^{\prime}$-diphenylmethane diisocyanate (MDI). Density of Ongronat 30-20 at temperature of $25^{\circ} \mathrm{C}$ was $1.23 \mathrm{~g} / \mathrm{cm}^{3}$, viscosity was $200 \mathrm{mPa} \mathrm{s}$, and content of $\mathrm{NCO}$ groups was $31.0 \%$. Catalyst in the process of foam preparation was anhydrous potassium acetate (POCh, Gliwice) applied in the form of 33\% solution in diethylene glycol-DEG (POCh, Gliwice) named Catalyst 12 and "DABCO 33LV" (triethylenediamine, Hülls, Germany) used as 33\% solution in DEG (diethylene glycol). Stabilizer of foam structure was poly(oxyalkylene siloxane) surface-active agent Silicone Tegostab 8460 (Witco, Sweden). Carbon dioxide formed in reaction of water with isocyanate groups acted as blowing agent. Moreover, liquid flame retardant tri(2-chloro-1-methylethyl) phosphate(V) with trade name "Roflam P" (Chemical Plants PCC Rokita S.A. in Brzeg Dolny) was introduced into foam composition. Lewis acid-tetraisopropyl titanate-was applied as catalyst in synthesis of polyols E14, E15, E16. Used catalyst trade name Tyzor TPT (Du Pont). It is transparent, light yellow, liquid product with freezing temperature of $19{ }^{\circ} \mathrm{C}$, highly sensitive to moisture. Tyzor TPT acts as a Lewis acid catalyst in processes such as esterification, transesterification, condensation and addition. It can also be used to effect adhesion promotion and cross-linking of polymers, or to form polymeric titanium dioxide layers used as a binder or coating. For synthesis of E14, E15, E16 used 2-hydroxypropane-1.2.3tricarboxylic acid (citric), Brenntag Poland LLC company in Kędzierzyn Koźle and diols: propane-1.2-diol and pentane-1.5-diol (POCh Gliwice).

\section{Synthesis of polyols (citrates E14, E15 and E16)}

The synthesis of polyols was conducted by mixing $1 \mathrm{~mol}$ (96 g) of 2-hydroxypropane-1.2.3-tricarboxylic [citric acid (CA)] with 4 mol propane-1.2-diol (144 g) for synthesis of E14 or with 4 mol propane-1.2-diol (114 g) for synthesis of E15 or with $3 \mathrm{~mol}$ of pentane-1.5-diol(156 g) for synthesis of E15-Table 1. Titanate

Table 1 The parameters of reaction process of citric acid with diols: CA-citric acid, 1.5-PD-pentane-1.5diol, 1.2-PG-propane-1.2-diol

\begin{tabular}{|c|c|c|c|c|c|c|c|c|c|}
\hline \multirow{3}{*}{$\begin{array}{l}\text { Symbol } \\
\text { of } \\
\text { product }\end{array}$} & \multicolumn{4}{|c|}{ Reagents } & \multicolumn{3}{|c|}{ Catalyst } & \multirow{3}{*}{$\begin{array}{l}\text { Temperature, } \\
{ }^{\circ} \mathrm{C}\end{array}$} & \multirow{3}{*}{$\begin{array}{l}\text { Time, } \\
\mathrm{h}\end{array}$} \\
\hline & \multirow{2}{*}{$\begin{array}{l}\text { CA, } \\
\mathrm{g}\end{array}$} & \multicolumn{2}{|l|}{ Diol } & \multirow{2}{*}{$\begin{array}{l}\text { KC: } \\
\text { diol }\end{array}$} & \multirow[t]{2}{*}{ Name } & \multicolumn{2}{|c|}{ Amount } & & \\
\hline & & Name & $\begin{array}{l}\text { Amount, } \\
\mathrm{g}\end{array}$ & & & $\mathrm{g}$ & $\%$ & & \\
\hline E14 & 96 & 1.2-PG & 144 & $1: 4$ & Tyzor & 0.36 & 0.06 & $155-143$ & 6.5 \\
\hline E15 & 96 & 1.2-PG & 114 & $1: 3$ & - & - & - & 154 & 9.5 \\
\hline E16 & 96 & $1.5-\mathrm{PD}$ & 156 & $1: 3$ & Tyzor & 0.096 & 0.04 & 161 & 8.5 \\
\hline
\end{tabular}


isobutyl (Tyzor TPT) in the amount of $0.06 \%$ (E14) or $0.04 \%$ (E16), was used as the catalyst in the synthesis.

The general scheme of the esterification of $1 \mathrm{~mol}$ of CA with $3 \mathrm{~mol}$ of diol can be presented as the following (Scheme 1). According to this scheme synthesized E15 and E16 products.

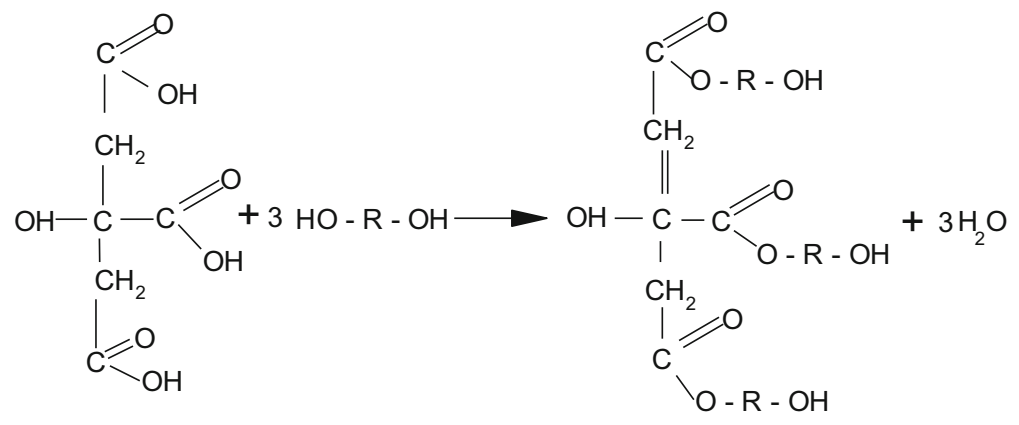

CA diol polyol (citrate) water

E14 product obtained according to Scheme 2 (1 mol CA reacted with 4 mol of the diol).

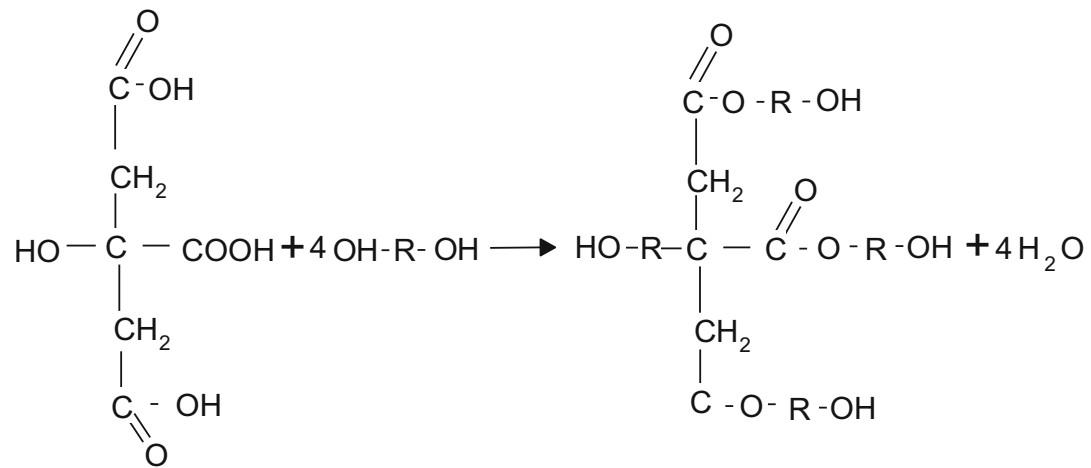

CA diol polyol (citrate) water

It was noticed, that the amount of distilled water is greater than the expected amount calculated based on the reaction's stoichiometry. This can be a sign of additional esterification reaction of the obtained hydroxyalkyl citrates with the nonreacted carboxyl groups of the neighboring particles. In addition, ethers can be created between the hydroxyl group of citric acid and the used glycol. It has been verified that the structure of the obtained products is more complex and, in one particle, can contain multiple structural fragments of citric acid and $\mathrm{O}-\mathrm{R}-\mathrm{O}$ bridges connecting citric acid's particles. 
The acid number (AN) of the obtained E14 product equals $52 \mathrm{mg} \mathrm{KOH} / \mathrm{g}$. This proves that the product contains not-reacted carboxyl groups. Based on the AN value, it is possible to calculate in what mass of the structural fragment is the carboxyl group (Scheme 3):

$$
56,100 / 52=1078.8 \mathrm{~g},
$$

where 52 is the acid number of E14.

The provided calculations show that it is a much greater mass than the mole mass of the E14 citrate, obtained according to Scheme 1 tri(hydroxyalkyl) (citrate). Based on that, it can be deduced that during the esterification, subsidiary reactions of step-growth polymerization of citric acid and diol particles occur. It is possible to calculate how many particles (moles) of citric acid comprise the composition of the structural fragment containing 1 mol of carboxyl groups (according to Eq. 4). If $x$ marks the number of citric acid moles and it is assumed that water is produced during step-growth polymerization reaction, it can be stated that (Scheme 4):

$$
192 x+4 \times 76 x-18 \times n=1078.8,
$$

where $x$ is the number of citric acid moles in a $1078.8 \mathrm{~g}$ structural fragment. $n$ is the number of moles for the water produced as a result of additional step-growth polymerization or etherification. 192 is the molar mass of citric acid. 76 is the molar mass of propane-1.2-diol. 18 is the molar mass of water.

Assuming that " $n$ " can equal from 1 to 4 , a value from 2.4 to 2.27 is calculated (assuming $x=2$ ). Based on the value of the hydroxyl number of the obtained product, it can be estimated how many moles of hydroxyl groups $(y)$ are in the analyzed structural fragment according to Scheme 5:

$$
y=280 \times 1078.8 / 56,100=5 \text { moles of } \mathrm{OH} \text { groups, }
$$

where 280 is the hydroxyl number of E14.

Knowing that $2 \mathrm{~mol}$ of citric acid react with $6 \mathrm{~mol}$ of diol (propane-1.2-diol), and that in the obtained product there is $1 \mathrm{~mol}$ of carboxyl groups and around $5 \mathrm{~mol}$ of hydroxyl groups, an approximate structure of the obtained product can be suggested (Scheme 6, E14 product):

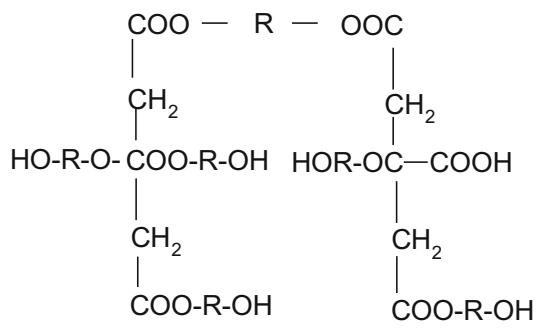


where

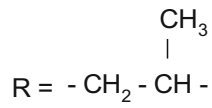

Using similar methods, the following structural formulas for E15 (Scheme 7) and E16 (Scheme 8) were determined:

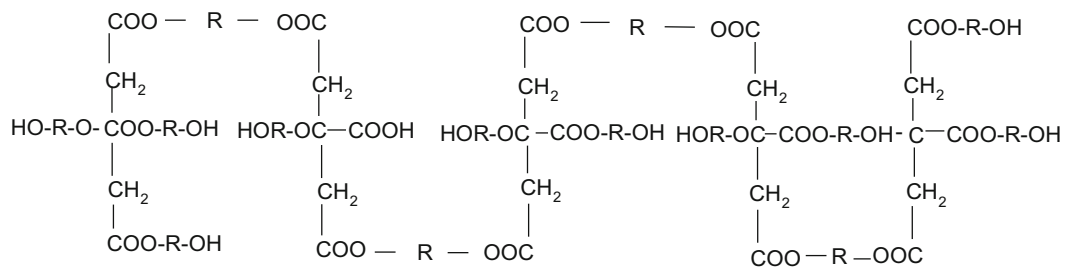

where $\mathrm{R}=-\mathrm{CH}_{2}-\stackrel{\stackrel{\mathrm{C}}{\mathrm{CH}}}{\mathrm{CH}}$ -

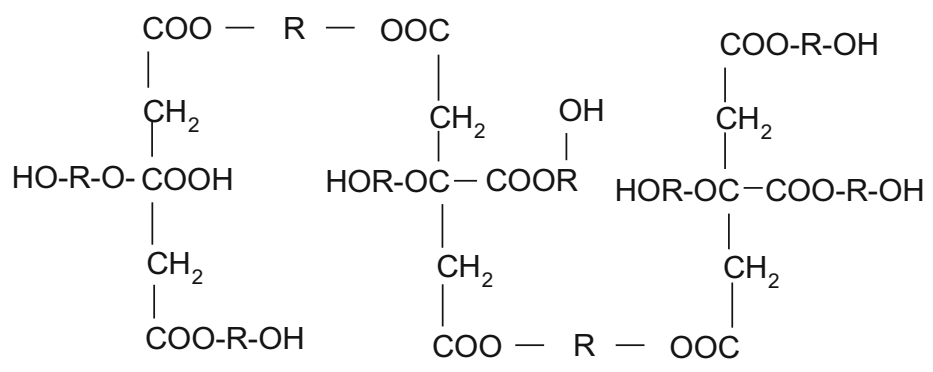

where $\mathrm{R}=-\left(\mathrm{CH}_{2}\right)_{5}-$

\section{Synthesis of rigid PUR-PIR foams}

Rigid PUR-PIR foams were produced using one-stage method from the twocomponent system according to the prepared recipes (Table 2). Polyol (Rokopol RF 551) was placed in one polypropylene container with $0.5 \mathrm{dm}^{3}$ volume. The same container was used for pouring polyol mixtures: Rokopol with E14 (foam series 14.1-14.5), or with E15 (foam series 15.1-15.5), or with E16 (foam series 16.1-16.6), along with auxiliary substances added to it. Electrical stirrer with $1800 \mathrm{rpm}$ rotation speed was used. This was the process of producing polyol premixes (A component) which further contained: Silicon Tegostab 8460$1.5 \mathrm{wt} \%$, DABCO-0.9 wt $\%$, Catalyst $12-2.1 \mathrm{wt} \%$, Roflam P-15 wt $\%$, Water-0.7 equivalent (eq.) The second container was used for measuring polyisocyanate (component $\mathrm{B}$ in amount 3.7 eq.). Then, the premixes were thoroughly mixed with component B using the stirrer for $10 \mathrm{~s}$. The reaction proceeds according to Scheme 9. 
Table 2 Recipes for foams from series 14, 15 and 16

\begin{tabular}{lllll}
\hline Foam & Rocopol RF 551 eq. (g) & Citrate E14 eq. (g) & Citrate E15 eq. (g) & Citrate E16 eq. (g) \\
\hline $\mathrm{W}$ & $1.0(66.8)$ & $0.0(0)$ & $0.0(0)$ & $0.0(0)$ \\
14.1 & $0.9(60.1)$ & $0.1(10.77)$ & - & - \\
14.2 & $0.8(53.4)$ & $0.2(21.53)$ & - & - \\
14.3 & $0.7(46.8)$ & $0.3(32.29)$ & - & - \\
14.4 & $0.6(40.1)$ & $0.4(43.06)$ & - & - \\
14.5 & $0.5(33.4)$ & $0.5(53.83)$ & - & - \\
15.1 & $0.9(60.1)$ & - & $0.1(9.29)$ & - \\
15.2 & $0.8(53.4)$ & - & $0.2(18.59)$ & - \\
15.3 & $0.7(46.8)$ & - & $0.3(27.87)$ & - \\
15.4 & $0.6(40.1)$ & - & $0.4(37.16)$ & - \\
15.5 & $0.5(33.4)$ & - & $0.5(46.45)$ & - \\
16.1 & $0.9(60.1)$ & - & - & $0.1(6.4)$ \\
16.2 & $0.8(53.4)$ & - & - & $0.2(12.9)$ \\
16.3 & $0.7(46.8)$ & - & - & $0.3(19.3)$ \\
16.4 & $0.6(40.1)$ & - & - & $0.4(25.7)$ \\
16.5 & $0.5(33.4)$ & - & & $0.5(32.2)$ \\
\hline
\end{tabular}
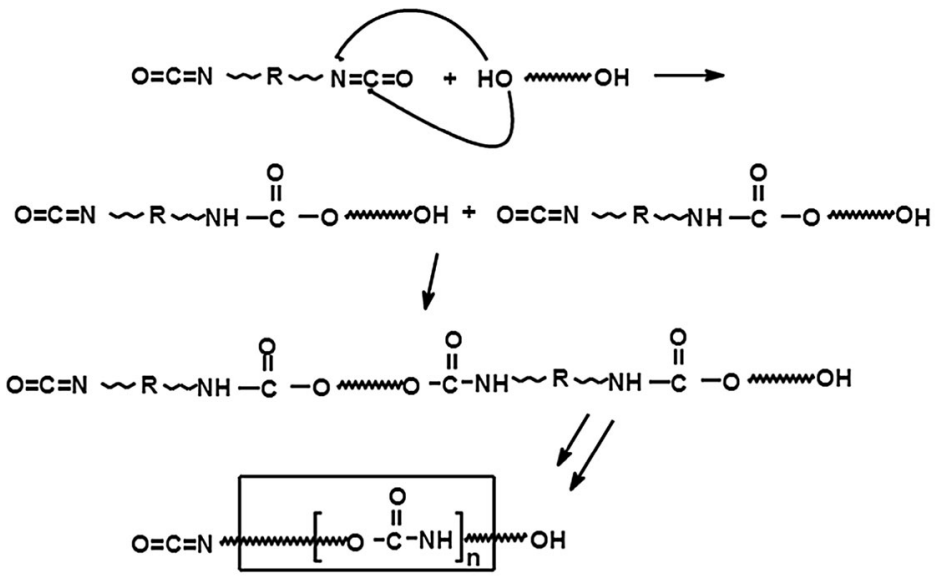

(9)

The mixture was put into a mould and the foam rising was observed. Open mould was used for the research, which is made of $3 \mathrm{~mm}$ thick steel with internal dimensions of $250 \times 250 \times 30(\mathrm{~mm})$. A so-called free rising took place in the mould. In the first stage, the standard foam ( $W$ reference foam) was produced, which did not contain any of the new compounds. Then the subsequent foams were created which contained from 0.1 to 0.5 eq. of one of the obtained polyols E14, E15 and 
E16 (Table 2). The following foam series were produced: 14.1-14.5, 15.1-15.5, 16.1-16.5. During the synthesis, the foaming process of the reactive mixture was monitored, measuring the appropriate technological times with a stop watch (always counted from the beginning of mixing of all of the components), i.e. start time, expansion time, gelation time. Start time-time measured until the moment of reaching "cream state". It starts being visible when the foam volume increases. Expansion time-time measured until the moment of reaching maximum foam volume. Gelation time-time measured until the moment of the foam free surface stops sticking to clean glass rod. The explanation of equivalent (eq.) was incorporated in previous articles, among others [40, 42].

\section{Analytical methods for raw materials for foams}

The raw materials used for the production of polyurethane materials need to have appropriate processing characteristics. They have significant meaning during the creation of the recipe for foam premixes, and during parameter determination for the production of polyurethane materials. Polyether and diisocyanate were characterized according to standards: ASTM D 2849-69 and ASTM D 1638-70. The examination of E14, E15 and E16 polyols was mostly focused on determining the hydroxyl number, the percentile amount of water and acid number. The hydroxyl number influences the amount of isocyanate necessary for creating urethane bonds. The amount of water in the polyol is needed for balancing the amount of water necessary for the foaming process. The acid number allowed for determination of chemical formula of the polyols. Hydroxyl number was performed according to WT/06/07/PURINOVA formula, Purinova Bydgoszcz. The water content was tested by Karl Fisher (PN-81/C-04959), in which the solvent used was a mixture of methanol and carbon tetrachloride in a 1:3 ratio, the titration reagent Combo. Marking is to dissolve the appropriate test portion of the product in Titraqual (Titrant for Titration) and potentiometric titration of the solution to the equivalence point.

\section{Analytical methods for foams}

The apparent density of the examined foams was determined as the ratio between foam mass to its geometrical volume, using cube samples with $50 \mathrm{~mm}$ edge, in compliance with ISO 845-1988 standard.

The behavior of the obtained foams in flame was determined with the following tests:

(a) Simplified flammability test chimney test (test vertical-Butler) according to ASTM D3014-73. Apparatus used for the flammability test of the vertical test consists of a vertical column with dimensions $300 \times 57 \times 54(\mathrm{~mm})$ which three walls are made of sheet metal, and the fourth is a movable window. The assay was performed on 6 samples with dimensions of $150 \times 19 \times 19 \mathrm{~mm}$. Before combustion of the sample was weighed to an accuracy of $0.0001 \mathrm{~mm}$, and then placed inside the chimney. Founded window and the sample were 
applied on the flame of the burner fueled by propane-butane at the time of $10 \mathrm{~s}$. Then the torch moved away and stopwatch measured the time free samples of smoking and retention (residue after burning) in the vertical test. The retention was calculated according to the equation (Scheme 10):

$$
R=\frac{m}{m_{0}} \times 100 \%
$$

where $R$ is the retention, $\% ; m_{0}$ is the mass of the sample before burning; $m$ is the mass of the sample after ignition, $\mathrm{g}$.

(b) Combustibility was tested based on a marker method in compliance with PNEN ISO 4589-2:2006 standard, using oxygen index module apparatus by concept equipment. The examination determined the boundary percentile volume of oxygen in a mixture of oxygen and nitrogen, needed for sustaining the burning of the sample in the shape of a $150 \times 13 \times 13(\mathrm{~mm})$ bar. The oxygen index is calculated in percentile value using the following equation (Scheme 11):

$$
\mathrm{OI}=\frac{\mathrm{O}_{2}}{\mathrm{~N}_{2}+\mathrm{O}_{2}} \times 100 \%,
$$

where $\mathrm{O}_{2}$ is the volumetric flow rate of oxygen for the boundary volume $\left[\mathrm{m}^{3} /\right.$ $\mathrm{h}], \mathrm{N}_{2}$ is the volumetric flow rate of nitrogen for the boundary oxygen volume $\left[\mathrm{m}^{3} / \mathrm{h}\right]$.

(c) Also, a burning examination using cone calorimeter was performed according to ISO 5660-1:2001 standard. During the examination, normalized samples with $100 \times 100 \times 6(\mathrm{~mm})$ dimensions were subjected to heat radiation of $30 \mathrm{~kW} / \mathrm{m}^{2}$. In addition, the following were marked: time until the burning reaction initiation, thermokinetic parameters, i.e. heat release rate and total heat released, as well as selected toxic and smoke-producing properties. The thermokinetic values were described based on the theory of oxygen use calorimetry, which states that for each $1 \mathrm{~g}$ of oxygen used, circa $13.1 \mathrm{~kJ}$ of heat is released with $\pm 5 \%$ precision. The examination was conducted for material samples positioned horizontally. The burning reaction was initiated by ignition. After the flame diminished, the examination ended.

(d) The burning of foam samples was observed with the help of Vigo System thermal imaging camera and the results were analyzed (Table 4). The burning of all samples was conducted with oxygen index of $26.5 \%$ to enable the burning of all foam materials, and the burning process analysis was made on at least three samples from the same material. The thermograms are represented in Fig. 4.

(e) The burning estimations using the horizontal method were done according to the PN-78 C-05012 standard. The method marks the speed of surface flame spreading on a sample with $150 \times 50 \times 13(\mathrm{~mm})$ dimensions, placed horizontally and exposed to a flame at one end (propane-butane burner). The speed of surface flame spreading is a speed at which the head of the flame 
moved on the surface of the examined sample of flammable material. During the examination, the sample foam is placed on a net fixed horizontally and a burner is placed at one side of the foam's end for $60 \mathrm{~s}$. A line is drawn across the $125 \mathrm{~mm}$ mark from the side where the burner is placed. The distance which the head of the flame covers and the time for the head to reach the marked line need to be noted. If the foam extinguishes before the flame reaches the marker, then the foam is categorized as self-extinguishing. If the foam keeps burning, an average burning time of the marked distance can be determined or the speed of flame spreading (in $\mathrm{mm} / \mathrm{s}$ ) based on the distance, the head of the flame covers in a specific time.

Heat properties of the foams are determined by examining their softening temperature. The Vicat apparatus is used for temperature measurement. The softening temperature, as the thermal resistance to compression, was marked using cube samples with $20 \mathrm{~mm}$ edge, according to the foam rising direction, in compliance with DIN 53424 standard. Foam samples were subjected to compressive load of $24.52 \mathrm{kPa}$ at $50{ }^{\circ} \mathrm{C}$ temperature for an hour. The softening temperature is the temperature at which the sample was compressed by $2 \mathrm{~mm}$.

\section{Results and discussion}

\section{Examination results for polyols (citrates) are represented in Table 3}

The parameters represented in Table 3 are necessary for the structural formula of the obtained polyols and preparation of foam recipes. The amount of water in the citrates does not exceed $1 \%$ for E15 and E16, that is why the amount of water needed for foaming was equal for both series accordingly to the equivalent (eq.) calculations. Only with the E14, the amount of water for the foam 14.4 and 14.5 was slightly lowered by the amount of water present in E14 polyol. According to the polyols hydroxyl number, their amount in the foam recipes was determined from 0.1 to 0.5 eq. Based on the acid and hydroxyl numbers, the structural formulas of the polyols were determined (Formulas 6-8).

The presented study focuses mostly on foam's burning properties. Butler test (vertical test) is one of the methods used for determining the flammability of

Table 3 Properties of E polyols (citrates)

\begin{tabular}{lllllll}
\hline Name & $\begin{array}{l}\text { Viscosity in } \\
25^{\circ} \mathrm{C}, \mathrm{mPa} \mathrm{s}\end{array}$ & $\begin{array}{l}\text { Density in } \\
25^{\circ} \mathrm{C}, \mathrm{g} / \mathrm{cm}^{3}\end{array}$ & $\begin{array}{l}\text { Hydroxyl } \\
\text { number, } \\
\mathrm{mgKOH} / \mathrm{g}\end{array}$ & $\begin{array}{l}\text { Acid number, } \\
\mathrm{mgKOH} / \mathrm{g}\end{array}$ & $\begin{array}{l}\text { Content of } \\
\text { water, \% }\end{array}$ & $\begin{array}{l}\text { Physical } \\
\text { state }\end{array}$ \\
\hline E14 & 3972 & 1.200 & 280 & 52 & 2.3 & Liquid \\
E15 & Not tested & Not tested & 300 & 23 & 1.2 & Solid \\
E16 & 10.364 & 1.053 & 436 & 43 & 0.98 & Liquid \\
\hline
\end{tabular}


polymer materials. During the study, sample foams were burned and by applying the standardized equation, the retention (remaining mass after burning) was calculated. The percentile retention value indicated the flammable properties of the foam material. The higher the retention, the less flammable the material. Figure 1 presents the relation between the foam's retention to the amount of new compounds in them. The Butlers flammability test examination showed no significant effect of the compound addition on the retention of E15 foam. Its value ranges from 80.9\% (15.1) to $94.3 \%$ (15.4). Series 15 had the lowest retention values in comparison to series 14 or 16. Foams from series 14 had the highest retention (from 91.7 to 96.5\%). The retention for series 16 ranges from $90.9 \%$ (16.1) to $94.1 \%$ (16.4).

Horizontal flammability test showed that the foams are self-extinguishing. The burning of the foams is a complicated and multistage process. One of the most objective methods of the assessment of burning is cone calorimetry. It enables the identification of burning properties for the material and the categorization of the phenomena during the burning process. The calorimeter uses Thornton principle, which states that the heat which is released during the burning of organic substances per unit amount of oxygen is a constant value and equals approximately $13.1 \mathrm{~kJ} / \mathrm{g}$. Using the measurement of momentary oxygen concentration in the fumes from the calorimeter, the amount of released heat at that moment is calculated per the unit amount of the surface of the examined sample or the unit amount of mass, and registered on a chart over time-Figs. 2, 3, 4.

The set of selected processing parameters of pyrolysis of rigid polyurethanepolyisocyanurate foams produced using new E14, E15 and E16 polyols are represented in Tables 4, 5, 6. Based on the examination results conducted in conditions corresponding for stage I fire development, it can be stated that the thermokinetic properties of the foams containing different citrates are similar to each other. The most varied results were reported for the smoke-producing properties for the foam containing 0.3 eq. of E16 compound (Table 5).

During the conducted burning test, using cone calorimeter method, the THR value was measured, which is the total amount of released heat by burning of the foam. The rate at which the heat is released (HRR) is an important parameter in the

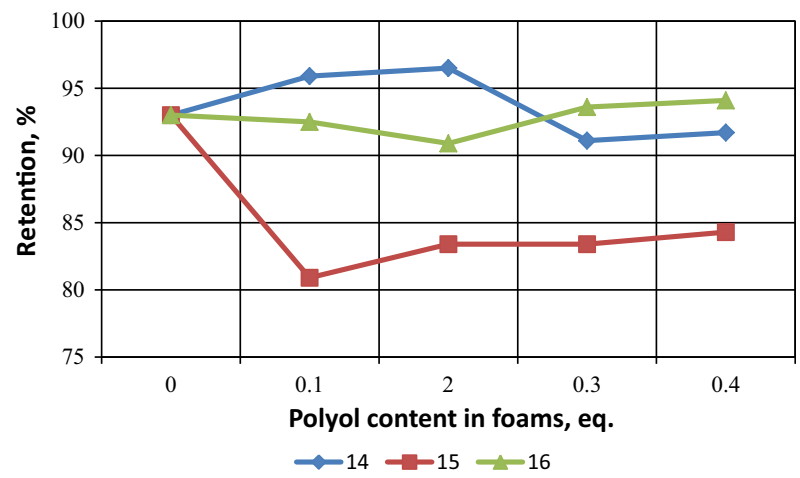

Fig. 1 The results of PUR-PIR foam burning examination using Butler technique 


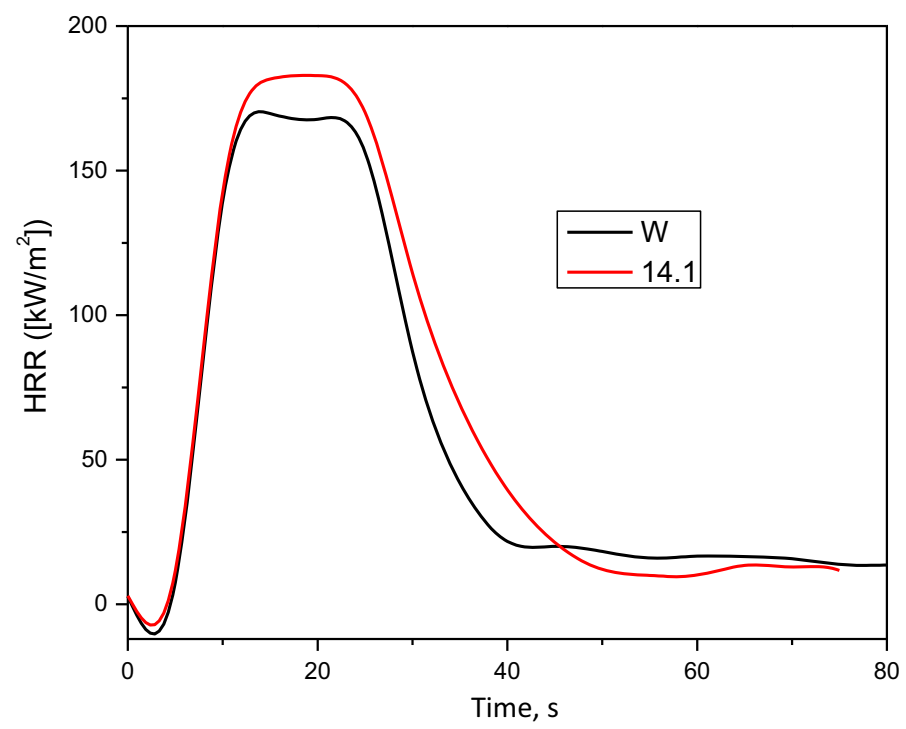

Fig. 2 HRR of series 14 foams

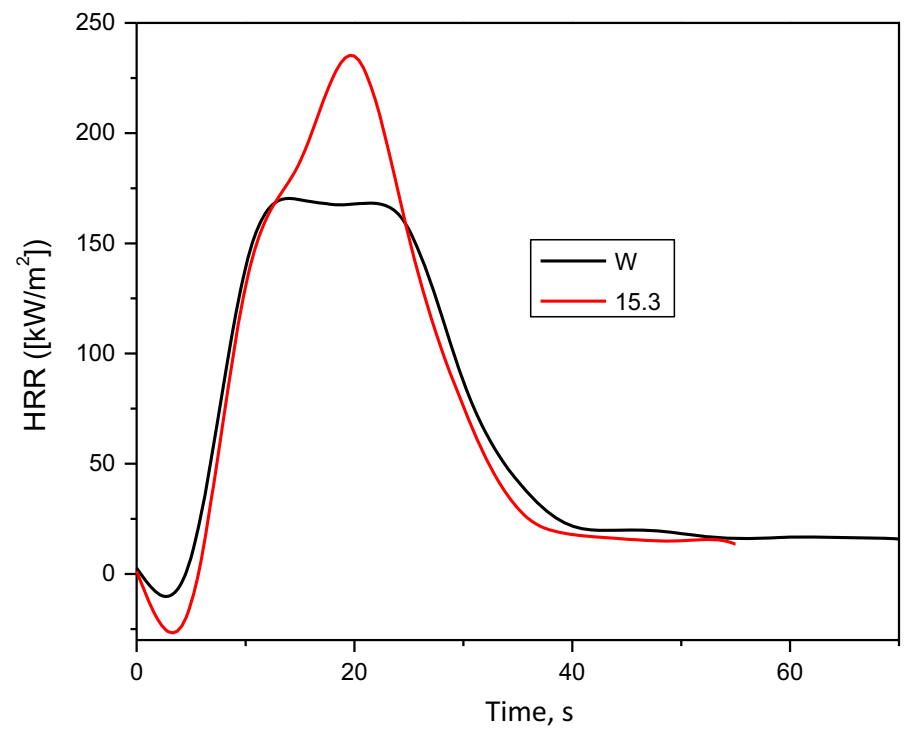

Fig. 3 HRR of series 15 foams

situation of actual fire. It is attributed to the surface pyrolysis of rigid polyurethane foams. It is considered to be the most critical parameter, determining the materials tendency for self-extinguishing. HRR values represented in Table 4 were determined for the values from the combustion moment until the end of the test. 


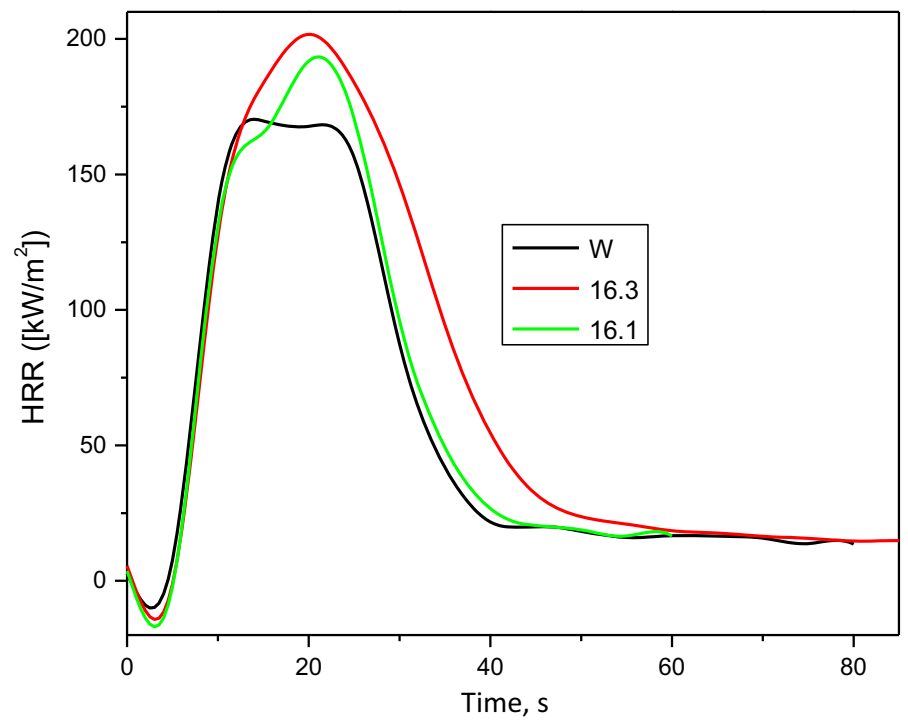

Fig. 4 HRR of series 16 foams

Table 4 Results of foam burning in cone calorimeter

\begin{tabular}{lllllc}
\hline Foam & $\mathrm{HRR}_{\max }, \mathrm{kW} / \mathrm{m}^{2}$ & $\mathrm{HRR}_{\mathrm{av}}, \mathrm{kW} / \mathrm{m}^{2}$ & $\mathrm{THR}, \mathrm{MJ} / \mathrm{m}^{2}$ & $\mathrm{TSR}, \mathrm{m}^{2} / \mathrm{m}^{2}$ & Average MLR, $\mathrm{g} / \mathrm{cm}^{2}$ \\
\hline$W$ & 169.74 & 60.79 & 4.6 & 269.4 & 9.08 \\
14.1 & 182.88 & 70.87 & 5.0 & 322.2 & 13.09 \\
15.3 & 234.96 & 85.96 & 4.3 & 298.7 & 14.62 \\
16.1 & 201.69 & 58.17 & 6.1 & 344.3 & 8.77 \\
16.3 & 191.84 & 81.28 & 4.5 & 302.5 & 11.35 \\
\hline
\end{tabular}

Table 5 The characteristic of gases generated during foam burning in cone calorimeter

\begin{tabular}{llllll}
\hline Foam & $\begin{array}{l}\text { Avg. amount of } \\
\mathrm{CO}_{2}, \mathrm{~kg} / \mathrm{kg}\end{array}$ & $\begin{array}{l}\mathrm{CO}_{2 \mathrm{max}}, \mathrm{kg} / \mathrm{kg} \text { in } \\
\text { time, } \mathrm{s}\end{array}$ & $\begin{array}{l}\mathrm{Avg} \text {. amount of } \\
\mathrm{CO}, \mathrm{kg} / \mathrm{kg}\end{array}$ & $\begin{array}{l}\mathrm{CO}_{\text {max }}, \mathrm{kg} / \mathrm{kg} \text { in } \\
\text { time, } \mathrm{s}\end{array}$ & $\begin{array}{l}\mathrm{CO} / \mathrm{CO}, \\
\mathrm{kg} / \mathrm{kg}\end{array}$ \\
\hline$W$ & 1.04 & 1.42 in $30 \mathrm{~s}$ & 0.1222 & 0.3453 in $60 \mathrm{~s}$ & 0.1175 \\
14.1 & 1.12 & 1.33 in $35 \mathrm{~s}$ & 0.1166 & 0.2675 in $55 \mathrm{~s}$ & 0.1041 \\
15.3 & 1.03 & 2.13 in $25 \mathrm{~s}$ & 0.1188 & 0.2775 in $40 \mathrm{~s}$ & 0.1153 \\
16.1 & 1.03 & 2.51 in $30 \mathrm{~s}$ & 0.1230 & 0.9404 in $80 \mathrm{~s}$ & 0.1194 \\
16.3 & 1.07 & 14.74 in $40 \mathrm{~s}$ & 0.1131 & 4.1667 in $40 \mathrm{~s}$ & 0.1057 \\
\hline
\end{tabular}


Table 6 Characteristic times during foam burning in cone calorimeter

\begin{tabular}{llllc}
\hline Foam & $t$ to combustion, $\mathrm{s}$ & $t$ to extinguishing, $\mathrm{s}$ & $t$ to $\mathrm{HRR}_{\max }, \mathrm{s}$ & $\mathrm{HRR}_{\max } / t, \mathrm{~kW} / \mathrm{m}^{2} \mathrm{~s}$ \\
\hline$W$ & 2 & 35 & 15 & 11.32 \\
14.1 & 2 & 43 & 20 & 9.14 \\
15.3 & 2 & 31 & 20 & 11.75 \\
16.1 & 3 & 50 & 20 & 10.08 \\
16.3 & 3 & 40 & 20 & 9.59 \\
\hline
\end{tabular}

The information on the burning mechanism is also provided by the shape of HRR curves, which illustrate the maximum value of heat release rate. It is an extremely important parameter, determining the ability of material's self-extinguishing characteristic during real fire. Figures 2, 3, 4 represent the curves of the heat release rate (HRR) in time for the obtained foams. The HRR curves for rigid PURPIR foams modified with E14, E15 and E16 polyols and for the non-modified foam, show the subsequent stages of the burning process. The initial heating of the samples can be observed, then the volatile elements and flammable gas products are released. The burning of the exhausted gases is the cause of increased amount of heat. The shape of the curves suggests that for the reference foam $(W)$ and for the modified foams, the increase in heat release rate (HRR) is rapid in both cases. The flame stabilizes and the burning decreases rather quickly. Modified foams burn reaching higher HRR value than the non-modified foam. The maximum HRR value increases along with the amount of E16 added to the foam (compare E16 and E16.5 foams-Fig. 4). After reaching the peak, there is a slower decrease in burning for modified foams, due to the elongation of time needed for reaching $H_{R R} R_{\max }$. It is clearly visible, that the addition of citrates to the foams affects the increase in average heat release rate $\mathrm{HRR}_{\mathrm{av}}$. The time to reach $\mathrm{HRR}_{\text {max }}$ also extends from $15 \mathrm{~s}$ for $\mathrm{W}$ foam, to $20 \mathrm{~s}$ for the rest.

Based on the examination, it has been determined, that the foams containing $\mathrm{E}$ compounds generate more heat than the reference foam $\mathrm{W}$-Table 6 . The maximum HRR for $\mathrm{W}$ foam is $169.74 \mathrm{~kW} / \mathrm{m}^{2}$, and for the rest it is in the range from $182.88 \mathrm{~kW} / \mathrm{m}^{2}$ (14.1 foam) to $234.96 \mathrm{~kW} / \mathrm{m}^{2}$ (15.3 foam). The average HRR $\left(\mathrm{HRR}_{\mathrm{av}}\right)$ ranges from $58.17 \mathrm{~kW} / \mathrm{m}^{2}$ (16.1 foam) to $85.96 \mathrm{~kW} / \mathrm{m}^{2}$ (15.3 foam).

The total heat release (THR) is also used for the safety assessment of the materials in real fires. For the examined foams, the THR values range from 4.3 MJ/ $\mathrm{m}^{2}$ (15.3 foam) to $6.1 \mathrm{MJ} / \mathrm{m}^{2}$ (16.1 foam). The highest amount of heat, equaling $6.1 \mathrm{MJ} / \mathrm{m}^{2}$, was released during the testing of 16.3 foam (foam with 0.3 eq. of E16 compound). The lower the amount of E16 (0.1 eq.) the lower the value of THR $\left(4.5 \mathrm{MJ} / \mathrm{m}^{2}\right)$, similar to the THR of the R foam $\left(4.6 \mathrm{MJ} / \mathrm{m}^{2}\right)$. The remaining foams show THR values closer to $\mathrm{W}$ foam THR values. 0.3 eq. of $\mathrm{E} 15$ compound results in THR of $4.3 \mathrm{MJ} / \mathrm{m}^{2}$ and for the foam containing 0.1 eq. of E14 compound, THR is $5.0 \mathrm{MJ} / \mathrm{m}^{2}$. 
Samples 14.1 and 16.1 have the highest intensity of total smoke released (TSR) Table 4. The total amount of released smoke during the burning of those samples was 322 and $344 \mathrm{~m}^{2} / \mathrm{m}^{2}$, respectively. Those values do not deviate much from the TSR values for the burning of the remaining foams, inducing the reference foam $W\left(269.4 \mathrm{~m}^{2} / \mathrm{m}^{2}\right)$.

The lowest average mass loss rate (MLR) equaling $8.77 \mathrm{~g} / \mathrm{s} \mathrm{m}^{2}$ was attributed to the 16.1 sample foam, and the highest average MLR value was for the 15.3 foam $\left(14.62 \mathrm{~g} / \mathrm{m}^{2} \mathrm{~s}\right)$-Table 6 . The average MLR of the reference foam was $9.08 \mathrm{~g} / \mathrm{m}^{2} \mathrm{~s}$.

The average amount of the exhausted CO for all foams was around $0.11-0.12 \mathrm{~kg} /$ $\mathrm{kg}$ of the sample (Table 5). The $\mathrm{CO}_{\max }$ values were reached in $40-80 \mathrm{~s}$ time. The addition of selected citrates to the polyol premixes causes the lowering of the maximum emission of the life threatening $\mathrm{CO}$ during foam burning (14.1 and 15.3).

The average amount of emitted $\mathrm{CO}_{2}$ for all foams was similar and was around $1 \mathrm{~kg} / \mathrm{kg}$ of the sample (Table 5). The $\mathrm{CO}_{2 \max }$ was reached in $25-40 \mathrm{~s}$ time. The highest maximum $\mathrm{CO}_{2}(14.74 \mathrm{~kg} / \mathrm{kg}$ in $40 \mathrm{~s})$ and $\mathrm{CO}(4.667 \mathrm{~kg} / \mathrm{kg}$ in $40 \mathrm{~s})$ emissions were noted for the 16.3 sample (the foam containing 0.3 eq. of E16 compound). At the same time, the foam containing 0.1 eq. of the E16 compound generates significantly lower amount of those gases in similar time $\left(\mathrm{CO}_{2}: 2.51\right.$ in $30 \mathrm{~s}, \mathrm{CO}: 0.9404$ in $80 \mathrm{~s}$ ). The values of the maximum $\mathrm{CO}_{2}$ and $\mathrm{CO}$ emissions for the remaining foams are close to the reference foam $W\left(\mathrm{CO}_{2}\right.$ emission) or lower (CO emission). The beneficial effect of the $\mathrm{E}$ compounds in the foams is represented by the lower values of the ratio between carbon oxide to carbon dioxide in those foams, than in comparison to the $\mathrm{CO} / \mathrm{CO}_{2}$ ratio in the $\mathrm{W}$ foam. Only in one case $(16.1$ foam) the $\mathrm{CO} / \mathrm{CO}_{2}$ ratio was a bit higher than in the $\mathrm{W}$ foam.

The combustion time for 14 and 15 series foam were the same as for the $\mathrm{W}$ foam and equaled $2 \mathrm{~s}$. The modification of the recipe with E16 compound resulted in longer combustion time for series 16 foams - to $3 \mathrm{~s}$. The addition of E14 and E15 did not have any effect on the combustion time prolongation, but it also did not cause its shortening. Such short time is a result of the foam's porous structure. For the obtained foams, the time is already shorter than for foams produced using hydrocarbons for foaming [41]. The extinguishing time for the sample was in the range of 31-50 s. Another important parameter, measured during the tests in cone calorimeter, is the time of reaching maximum total heat release ( $t$ to $\left.\operatorname{HRR}_{\max }\right)$. It was $20 \mathrm{~s}$ for the examined foam samples containing E polyols, and it was $15 \mathrm{~s}$ for the $\mathrm{R}$ foam.

The ratio of $H R R_{\max }$ value to time in which the maximum is reached $\left(\mathrm{HRR}_{\max } / t\right)$ is used for comparison of the behavior of different materials in flame. The smaller the value of this ratio, the safer the material is considered to be. The ratio of $\mathrm{HRR}_{\max }$ value to time in which it was reached (Table 6) is in the range of 9.14-11.75 k W/ $\mathrm{m}^{2} \mathrm{~s}$. The highest value was reached by the reference foam.

The value of the oxygen index (OI) was determined, which is the percentage value of oxygen in the nitrogen mixture, which sustains the burning of the sample (Table 7). It mainly reflects the degree of flammability of the volatile products of material decomposition. The oxygen index for reference foam is $23.9 \%$. After the modification of PUR-PIR foam with E14, E15 and E16 compounds, similar oxygen index values can be observed in the range of $23.8-24.0 \%$. There was no observable 
Table 7 Oxygen index of PUR-PIR foams

\begin{tabular}{ll}
\hline Foam & Oxygen index, $\%$ \\
\hline$W$ & 23.9 \\
14.1 & 24.3 \\
14.3 & 24.0 \\
15.2 & 24.0 \\
15.3 & 23.8 \\
16.1 & 23.9 \\
16.2 & 23.6 \\
16.3 & 24.0 \\
\hline
\end{tabular}

correlation between the oxygen index and the amount of E citrate in the foam. The type of used polyol also did not have any significant effect on the OI value.

Using the oxygen index method, it was confirmed that the presence of the new compound in the PUR-PIR foam does not affect negatively the foam's flammability.

The foam burning process observation was made using thermal imaging camera. Figure 5 represents the thermograms of foams which were the closest to the average values. The temperature layout indicated a rapid course of the foams' burning process. It was observed that the lower part of the flame which has contact with sample's surface does not show a wide range of temperatures. In the upper flame part the temperature range is wider due to the turbulences caused by the rapid transport of the gas mass from the burning sample.

Table 8 represents selected values describing the foam burning process. $T_{\max }$ is the maximum burning temperature of the sample registered by the thermal imaging camera. $T_{\mathrm{av}}$ is the average temperature until the thermographical extinguishing of the sample during burning (the last occurrence of a temperature exceeding $400{ }^{\circ} \mathrm{C}$ ). The reference foam had the highest average temperature during burning $\left(623{ }^{\circ} \mathrm{C}\right)$. The addition of larger amounts of the E compound causes the lowering of the $T_{\mathrm{av}}$, e.g. to $592{ }^{\circ} \mathrm{C}$ (14.3 foam). It was noted, that the maximum temperature during burning of the reference foam $W$ reached $661{ }^{\circ} \mathrm{C}$ in $17 \mathrm{~s}$. The addition of 0.1 or 0.2 eq. of the new $\mathrm{E}$ compounds caused the prolongation of the occurring time for the maximum temperature during burning, from $13 \mathrm{~s}$ ( $W$ foam) to $16 \mathrm{~s}$ (14.1 foam), $14 \mathrm{~s}$ (15.2 foam) and $15 \mathrm{~s}$ (16.1 foam). Also the burning times for foams with $\mathrm{E}$ polyols were longer. The highest increase (from $17 \mathrm{~s}$ for $W$ foam) was noted for the foams containing E15 compound (up to 26 s for 15.2 foam). The time of burning for $5 \mathrm{~cm}$ sample either got shorter after the addition of $\mathrm{E}$ citrates, or was equal to the burning time of $W$ foam $(9 \mathrm{~s})$. The average surface of the temperature peak until the moment of thermographical extinguishing of the sample was slightly larger for the foams with the $\mathrm{E}$ compound, than for the reference foam $(40,323)$. The largest average surface was registered for the 14.1 foam $(45,583)$.

Thermal properties of the foams were determined by examining their softening temperature using Vicat method. The influence of E polyols on the foam softening temperature was assessed. The examined softening temperature $\left(T_{\mathrm{s}}\right)$ decreased with the increased amount of E14, E15 and E16 compounds used in the polyol premixes 

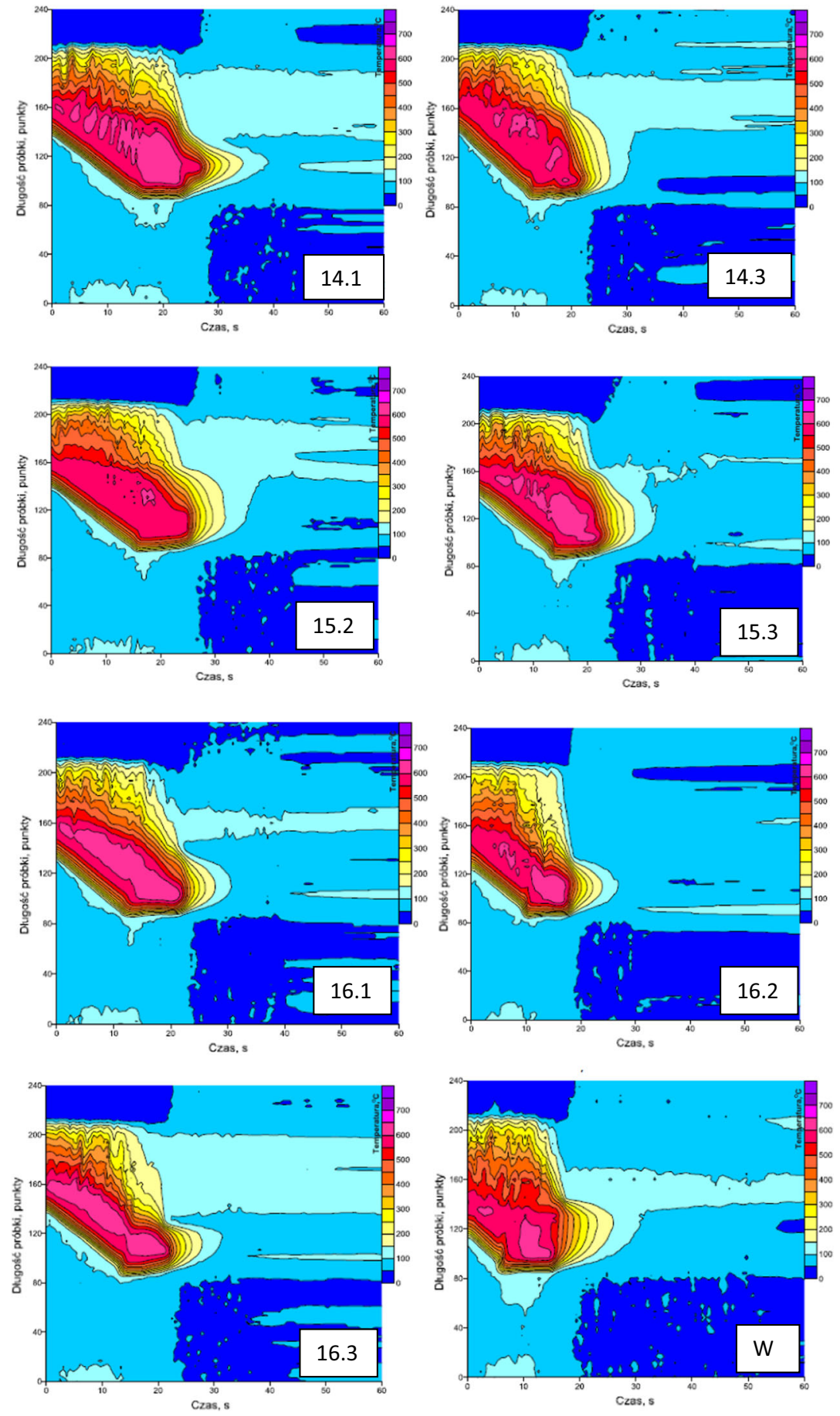

Fig. 5 Thermal images of foams: 14, 15 and 16 series and the reference $W$ foam 


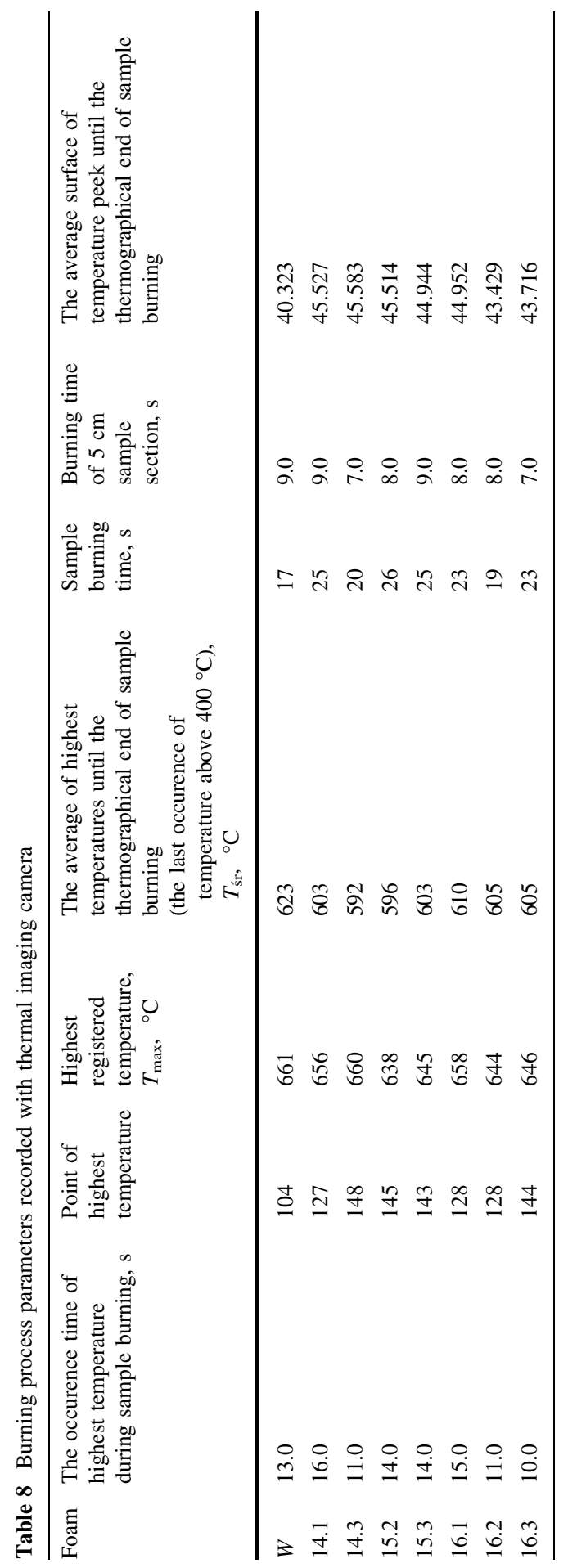




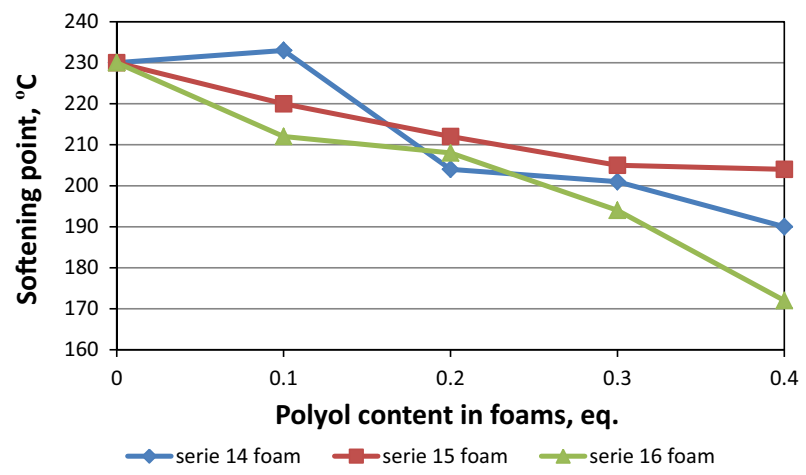

Fig. 6 The relation between the foam softening temperature and the amount of E polyol

(Fig. 6) from 230 to 190,204 and $172{ }^{\circ} \mathrm{C}$, respectively. The lowest decrease was observed for the foams from series 16.

\section{Conclusions}

Due to a very specific porous surface of the polyurethane material, it is classified as a flammable material. The search of the method for lowering the flammability of PUR-PIR foams is a very important subject. The conducted flammability examinations confirmed, that the use of citrates, containing $-\mathrm{OH}$ groups in the molecular structure, decrease foam flammability or does not affect their flame resistance in comparison to the foam containing industrial polyol. The addition of citric acid compounds causes the prolongation of foams' permanent combustion time and the increase of their oxygen index and retention. The maximum burning temperature for foams containing the $\mathrm{E}$ polyols decreases in comparison to the reference foam. The addition of 0.1 or 0.2 eq. of the new E compounds caused the prolongation of the occurring time for the maximum temperature during burning, from $13 \mathrm{~s}$ ( $W$ foam) to $16 \mathrm{~s}$ (14.1 foam), $14 \mathrm{~s}$ (15.2 foam) and $15 \mathrm{~s}$ (16.1 foam). The ratio of $\mathrm{HRR}_{\max }$ value to time in which it was reached is in the range of 9.14-11.75 k W/m ${ }^{2} \mathrm{~s}$. The oxygen index (OI) for reference foam was $23.9 \%$. Similar IO values can be observed for foams with E14, E15 and E16 compounds (in the range of $23.8-24.0 \%$ ). The research proved, that the modification of polyol premixes in polyurethane foam production allows for obtaining foam materials with parameters similar to materials produced based on an industrial polyol. The use of citric acid for obtaining rigid polyurethane-polyisocyanurate foams may affect the lowering of the raw material price for the production of polyurethanes and the lowering of foam production costs. The savings are directly related to the use of a citric acid, which is cheaper than the carboxyl acids (and mixtures of those acids), vegetable oils or mineral oils (e.g. Castrol) used currently. The second aspect of production costs decrease is the lowering of foam flammability without the need to use expensive flame retardants. 
Open Access This article is distributed under the terms of the Creative Commons Attribution 4.0 International License (http://creativecommons.org/licenses/by/4.0/), which permits unrestricted use, distribution, and reproduction in any medium, provided you give appropriate credit to the original author(s) and the source, provide a link to the Creative Commons license, and indicate if changes were made.

\section{References}

1. Riegert D, Diechciarz A, Auguścik M, Klapsa W, Examination of fire properties of polyurethane materials (in polish). In: VI scientific conference, Pomerania—plast polymer materials, January 7-10 2016, Międzyzdroje, College Publisher ZUT in Szczecin 2016, pp 273-274

2. Journal of Laws 2002, No 75, item 690, Minister of Infrastructure Regulations of April 12th 2002 on the technical conditions of buildings and their location (in polish)

3. Paciorek-Sadowska J, Czupryński B, Liszkowska J (2010) New boroorganic polyol for the production of rigid polyurethane-polyisocyanurate foams. Polymers (in polish) 55(1):29-32

4. Czupryński B (2004) Chemistry and polyurethane technology issues (in polish). Bydgoszcz Academy Publishing House, Bydgoszcz, pp 83-111

5. Pólka M (2013) The influence of burning products, in different stages of the fire, on people. FireFight Digest (in polish) 11:12-13

6. Bourbigota S, Duquesnea S (2007) Fire retardant polymers: recent developments and opportunities. J Mater Chem 17:2283-2300. doi:10.1039/B702511D

7. Brzozowski ZK, Kijeńska D, Zatorski W (2002) New achievements in fire-safe polyurethane foams. Des Monomers Polym 2-3:183-193

8. Paciorek-Sadowska J, Czupryński B, Liszkowska J (2010) New polyol for production of rigid polyurethane-polyisocyanurate foams part 2: preparation of rigid polyurethane-polyisocyanurate foams with the new polyol. J Polym Eng 30(3-4):229-244. doi:10.1515/POLYENG.2010.30.3-4.229

9. Riegert D (2013) The ability to modification the properties of flammable plastics. Fire-Fight Saf Technol (in polish) 30(2):51-57

10. Iwko J (2007) The safety of using plastic materials with regards to their flammability. Mechanic (in polish) 10:1-3

11. Profit-Szczepańska M, Półka M (2003) Mathematical analysis of burning process of polyester compositions, using Numajiri-Furukawa method. Polymers (in polish) 48(7-8):545-548

12. Iwko J (2009) The behaviour of plastic materials during fire 1. Flammability and fire properties of plastic materials. Plast Mater Chem (in polish) 3:38-42

13. Paciorek-Sadowska J, Czupryński B, Liszkowska J, Jaskółowski W (2010) New boroorganic polyol for the production of rigid polyurethane-polyisocyanurate foams. Polymers (in polish) 55(2):99-105

14. Czupryński B, Paciorek-Sadowska J, Liszkowska J (2002) Effect of selected boranes on properties of rigid polyurethane-polyisocyanurate foams. J Polym Eng 22(1):59-74. doi:10.1515/POLYENG. 2002.22.1.59

15. Czupryński B, Paciorek-Sadowska J, Liszkowska J (2002) The effect of tri(1-chloro-3-etoxy-propane-2-ol) borate on the properties of rigid polyurethane-polyisocyanurate foams. Polimery 47(10):727-729

16. Nagrodzka M, Małozięć D (2010) The ability to modification the properties of flammable plastics. Fire-Fight Saf Technol (in polish) 2:51-57

17. Sawicki T (2003) Plastic materials and fire hazards. Saf Workplace (in polish) 7-8:43-45

18. Czupryński B, Liszkowska J, Sadowska J (2001) Selected issues regarding the flammability of some plastic materials and methods of identifying their burning products. Ecol Technol (in polish) 9(4):105-113

19. Sadowska J, Czupryński B, Liszkowska J (2015) Boron-containing fire retardant rigid polyurethanepolyisocyanurate foams: part I-polyol precursors based on boric acid and di(hydroxymethyl)urea derivatives. J Fire Sci 33(1):37-47. doi:10.1177/0734904114554384

20. Sadowska J, Czupryński B, Liszkowska J (2015) Boron-containing fire retardant rigid polyurethanepolyisocyanurate foams: part II—preparation and evaluation. J Fire Sci 33(1):48-68. doi:10.1177/ 0734904114554384

21. Reymore HE, Lockwood RJ, Ulrich H (1978) Novel isocyanurate foams containing no flame retardant additives. J Cell Plast 14(6):332-340 
22. Czupryński B, Paciorek-Sadowska J, Liszkowska J (2006) Studies on effect of tri(2-hydroxypropyl), tri(2-hydroxybutyl) and tri(hydroxythiodiethylene) borates on thermal and heat properties of rigid polyurethane-polyisocyanurate foams. Chin J Chem 24(12):1796

23. Prociak A (2008) New generation thermoinsulating polyurethane materials (in polish). PK Publishing House, Cracow, pp 42-43

24. Głowacz-Czerwonka D, Oleksy M (2016) Self-extinguishing polyurethane foams from polyols with different hydroxyl number (in polish). In: Conference: modification of the polymers. Status and prospects in 2015. Publisher Tempo s.c., Wrocław 2015, pp 163-164

25. Rybiński P, Janowska G (2013) Flammability and other properties of elastomer materials and nanomaterials. Part I. Elastomer nanocomposites with montmorillonite or halloysite. Polymers (in polish) 58(5):327-341

26. Zatorski W (2014) Dangerous substances emitted during the processing of plastic materials with lowered flammability containing antipirenes and nanomolecules (in polish). CIOP-PIB Publishing, Warsaw, pp 1-28

27. Kabir ME, Saha MC, Jeelani S (2007) Effect of ultrasound sonication in carbon nanofibers/polyurethane foam composite. Mater Sci Eng A 459:111-116

28. Dolomanova V, Rauhe J, Ch M, Jensen LR, Pyrz R, Timmons AB (2011) Mechanical properties and morphology of nano-reinforced rigid PU foam. J Cell Plast 47(1):81-93

29. Piszczyk Ł, Strankowski M, Danowska M, Haponiuk JT (2012) Preparation and characterization of rigid polyurethane-polyglycerol nanocomposite foams. Eur Polym J 48(10):1726-1733

30. Nikje MMA, Noruzian M, Moghaddam ST (2015) Investigation of Fe304/AEAP supermagnetic nanoparticles on the morphological, thermal and magnetite behavior of polyurethane rigid foam nanocomposites. Polimers (in polish) 60(1):26-32. doi:10.14314/polimery.2015.026

31. Fan H, Tekeei A, Suppes GJ, Hsieh FH (2013) Rigid polyurethane foams made from high viscosity soy-polyols. J Appl Polym Sci 127:1623

32. Choi J, Kim D, Ryu K, Lee HI, Jeong H, Shin C, Kim J, Kim B (2011) Functionalized graphene sheet/polyurethane nanocomposites: effect of particle size on physical properties. Macromol Res 19:809

33. Pei A, Malho JM, Ruokolainen J, Zhou Q, Berglund LA (2011) Strong nanocomposite reinforcement effects in polyurethane elastomer with low volume fraction of cellulose nanocrystals. Macromolecules 44:4422-4427

34. Cabulis U, Sevastyanova I, Andersons J, Beverte I (2014) Rapeseed oil-based rigid polyisocyanurate foams modified with nanoparticles of various type. Polimers (in polish) 59(3):207-212. doi:10. 14314/polimery.2014.207

35. Zatorski W, Brzozowski Z, Kolbrecki A (2008) New developments in chemical modification of firesafe rigid polyurethane foams. Polym Degrad Stab 93:2071-2076

36. Olejnik M (2008) Polymer nanocomposites with montmorillonite—production, assessment methods, properties and application. Technol Text Prod (in polish) 16(3-4):67-74

37. Kacperski M (2003) Polymer nanocomposites part II. Nanocomposites produced from thermoplastic polymers and phyllosilicates. Polymers (in polish) 48(2):85-90

38. Horrocks AR, Price D (2008) Advances in fire retardant material. Woodhead Publishing Limited, Cambridge, pp 125-153

39. Obłój-Muzaj M (2000) The behaviour of poly(vinyl chloride) in fire. Polymers (in polish) 45(10):720-722

40. Liszkowska J, Czupryński B, Paciorek-Sadowska J (2015) Different catalysts for new polyols for rigid PUR-PIR foams. Polish J Chem Technol 4:134-141. doi:10.1515/pjct-2015-0080

41. Matusinovic Z, Wilkie CA (2012) Fire retardancy and morphology of layered double hydroxide nanocomposites: a review. J Mater Chem 22:18701-18704

42. Liszkowska J (2016) Citric acid used in the production of polyols for rigid PUR-PIR foams. Polym Bull (On-line). doi:10.1007/s00289-016-1705-4

43. Liszkowska J, Czupryński B, Paciorek-Sadowska J (2015) Synthesis of rigid foams PUR-PIR with a new polyol. Chem Eng Equipment (in polish) 54(1):10-11

44. Liszkowska J, Czupryński B, Paciorek-Sadowska J (2016) Material recycling of PUR-PIR foams produced based on hydroxylalkyl citrates. In: VI scientific conference, Pomerania-plast polymer materials, January 7-10 2016, Międzyzdroje, College Publisher ZUT in Szczecin 2016, pp 109-110

45. Liszkowska J, Czupryński B, Paciorek-Sadowska J (2016) Raw material recycling of PUR-PIR foams produced based on hydroxylalkyl citrates. In: VI scientific conference, Pomerania-Plast 
polymer materials, January 7-10 2016, Międzyzdroje, College Publisher ZUT in Szczecin 2016, pp 211-212

46. Liszkowska J, Czupryński B, Paciorek-Sadowska J (2015) Synthesis and properties of new condensation product of citric acid for rigid PUR-PIR foams. In: Conference: modification of the polymers. Status and prospects in 2015. Publisher Tempo s.c., Wrocław, pp 129-132

47. Liszkowska J, Czupryński B, Paciorek-Sadowska J (2015) The effect of citric acid condensation on the properties of the rigid PUR-PIR foam. In: Conference: modification of the polymers. Status and prospects in 2015. Publisher Tempo s.c., Wrocław, pp 133-136 